\title{
Construction of a dataset for the gene $n r L S U$ to support the identification of Cantharellus at Langbian Mountain, Lam Dong
}

Tran Van Hanh ${ }^{1}$, Vu Tien Luyen ${ }^{1}$, Phan Huu Hung ${ }^{2}$, Truong Binh Nguyen ${ }^{3}$, Tran Duc Vinh ${ }^{4}$, Lao Duc Thuan ${ }^{4}$, Le Huyen Ai Thuy ${ }^{*}$

${ }^{1}$ University of Science, VNU-HCM, Vietnam

${ }^{2}$ Tay Nguyen Institute of Scientific Research, Vietnam Academy of Science and Technology, Vietnam

${ }^{3}$ Da Lat University, Viet Nam

${ }^{4}$ Ho Chi Minh City Open University, Viet Nam

*Corresponding author: thuy.lha@ou.edu.vn

ARTICLE INFO

ABSTRACT

DOI: $10.46223 / \mathrm{HCMCOUJS.}$ tech.en.8.2.342.2018

Received: February $6^{\text {th }}, 2018$

Revised: May $7^{\text {th }}, 2018$

Accepted: May $14^{\text {th }}, 2018$

Keywords:

Cantharellus, Large Subunit (LSU) of rDNA, the phylogenetic tree
Fungal species of Cantharellales order are found worldwide including Europe, Africa, Asia, and North America. This clade includes two smaller, separate, but closely related genera Cantharellus and Craterellus. Cantharellus was firstly identified in the middle of the $17^{\text {th }}$ century. Besides traditional classification based on morphology, molecular phylogeny of the nuclear ribosomal large subunit gene $(n r L S U)$ can be an effective tool to provide more information during species identification for this group. In this current report, a dataset of the $n r L S U$ gene including 60 sequences of Cantharellus species and 1 sequence belonging to Craterellus (outgroup), was obtained from Genbank. Phylogenetic analyses by MEGA 6.0 showed a monophyletic relationship between the six well-established clades, namely Cantharellus (Clade 1), Rubrinus (Clade 2), Cinnabarinus (Clade 3), Parvocantharellus (Clade 4), Pseudocantharellus (Clade 5) and subgenus Afrocantharellus (Clade 6) similar to that of morphological classification. Therefore, this dataset is efficient to support the identification of the fungal samples, collected at the Langbian Mountain, Lam Dong.

\section{Introduction}

Cantharellus Adans.: Fr (Family Cantharellaceae J. Schröt.). as circumscribe in the middle of the $17^{\text {th }}$ century, belong to Cantharellales order (Cantharallaceae, Cantharelloid clade), collected from Europe, Africa, Asia and North America, in detail, 23 species in North America, 7 species in South America, 7 species in Australia, 9 species in Europe, 3 species in New Zealand, 46 species in Africa, and 19 species in Asia (Buyck \& Hofstetter, 2011; 
Eyssartier, Stubbe, Walleyn, \& Verbeken, 2009; Shao et al., 2014; Tibuhwa, Saviæ, Tibell, \& Kivaisi, 2012). Morphology of Cantharellus was characterized as the overall vase-like or infundibuliform shaped, the superficially resemble agarics (gilled mushrooms), but the surface is smooth, wrinkled, or follicle-shaped (Kumari, Upadhyay, \& Reddy, 2011). These species are mostly ectomycorrhizal fungi, forming a mutually beneficial relationship with the roots and other trees, primarily within the beech family and pine family. Cantharellus has been considered to have high economic value, such as Craterellus cornucopioides, Cantharellus formosus, Craterellus tubaeformis, Cantharellus minor (Redhead, Norvell, \& Danell, 1997; Arora \& Dunham, 2008), with significant levels of proteins, lipids, minerals, vitamins and some neutraceutical compounds. (Pilz, Norvell, Danell, \& Molina, 2003).

The Cantharellus and Craterellus have been recognized as two closely related genus (Fries, 1838; Persoon, 1797), which may be recognized by their lack of division into cap and stipe, and their rudimentary. Recent phylogenetic studies from sequence analyze suggested to be useful to study fungal taxonomy and diversity. These include the small subunit (SSU), large subunit (LSU) of rRNA, the internal transcribed spacer region (ITS), etc (Buyck \& Hofstetter, 2011; Feibelman, Doudrick, Cibula, \& Bennett, 1997; Kumari et al., 2011) Among that, phylogenetic analysis of the nuclear large subunit rRNA (LSU) in Cantharellus has supported to clarify the identity of different species (Arora \& Dunham, 2008; Dunham \& Molina, 2003; Redhead et al., 1997). In order to resolve the internal or external evolutionary relationship of Cantharellaceae, Feibelman et al. (1997) studied the phylogenetic relationships within the Cantharellaceae inferred from sequence analysis of nuclear large subunit rDNA. Sequence analyses demonstrated that Cantharellus and Craterellus should be treated as distinct genera on the classification of Cantharellus clade (Buyck \& Hofstetter, 2011).

The main objective of the current study is to establish a dataset to support the identification of Cantharellus. In a further study, it will be applied in the identification of the Cantharellus clade at Langbian mountain, Lam Dong province in the following publications.

\section{Materials and methods}

\subsection{Taxa and sequence collection}

Sequence of $n r L S U$ was collected from Genbank (NCBI) and previously published data. The data set was constructed according to Figure. 1 The $n r L S U$ is noted with strain, accession number, name of taxon and locality. 


\section{Finding a information, combined bioinformatics}

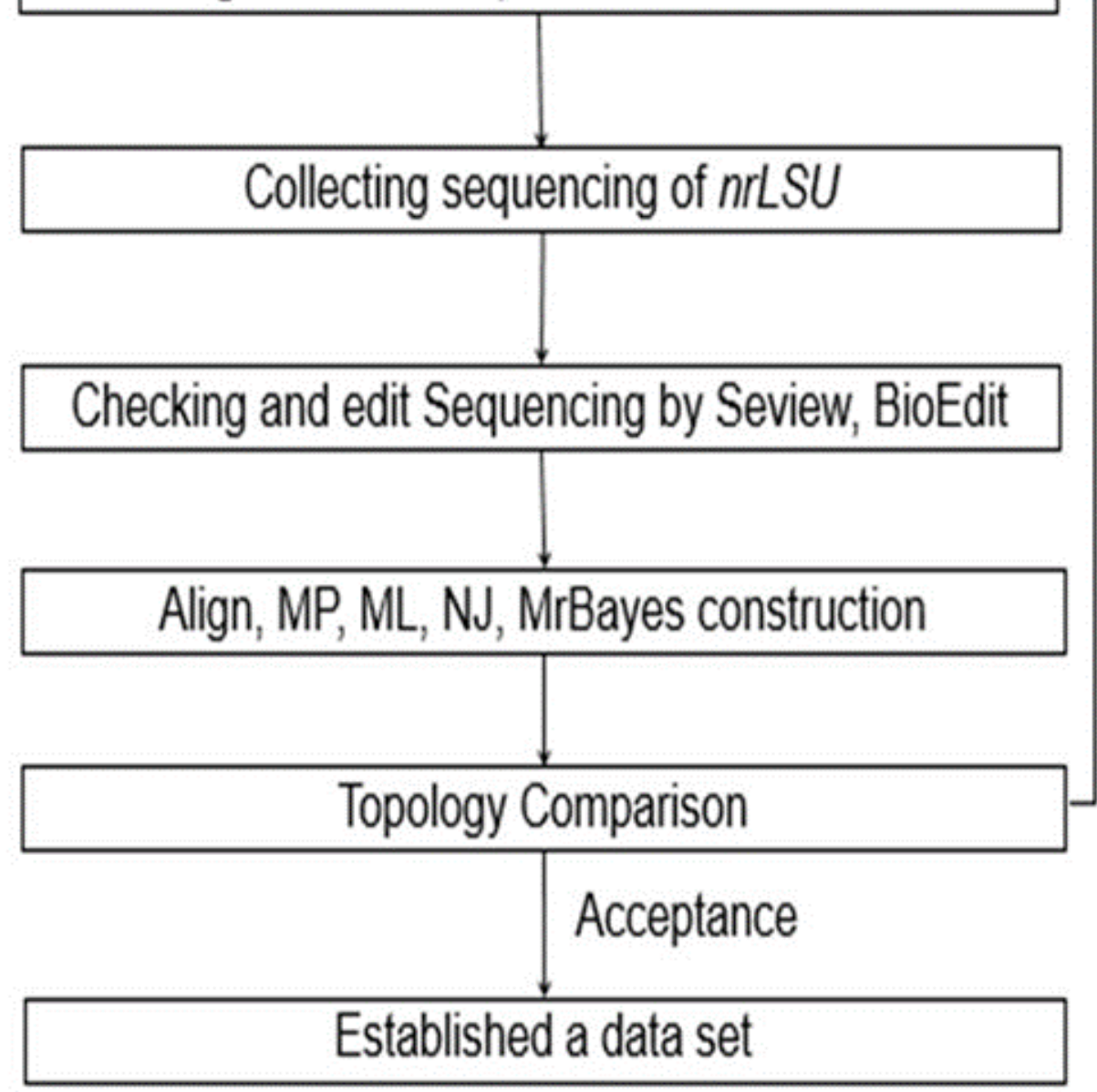

\section{Rejection}

Figure 1. The protocol for construction of nrLSU data set

\subsection{Phylogenetic analysis}

The phylogenetic tree was constructed, based on the neighbor-joining (NJ) and maximum parsimony (MP) maximum likelihood (ML) methods, by using Molecular Evolutionary Genetics Analysis (MEGA) version 6.0. Additionally, the best evolution model was predicted by using jModelTest.

\section{Results and discussion}

\subsection{The systematic dataset}

The final $n r L S U$ rDNA sequence data set, including 60 sequences of Cantharellus and 1 sequence belonged to Craterellus (served as outgroup), were collected from Genbank (NCBI) (listed in Table 1). In detail, the $n r L S U$ rDNA was collected from different countries; included 7 sequences in Tanzania, 21 sequences in Madagascar, 2 sequences in Zambia, 17 sequences in USA, 6 sequences in Slovakia, 3 sequencings in France, notably, only 4 sequences in Malaysia; within the average length of 1424 nucleotides. The best substitution for phylogenetic analysis was predicted by using $\mathrm{j}$ Model Test. 


\section{Table 1}

The data of $n r L S U$ gene was used for the construction of phylogenetic trees

\begin{tabular}{|c|c|c|c|c|}
\hline No. & Accession & Taxon & Strain & Locality \\
\hline 1 & KF294621 & Cantharellus addaiensis Henn. 1898 & BB 98.057 & Tanzania \\
\hline 2 & KF294667 & Cantharellus addaiensis & BB 98.033 & Tanzania \\
\hline 3 & KF294606 & Cantharellus aff. congolensis & BB 06.176 & Madagascar \\
\hline 4 & KF294608 & Cantharellus aff. congolensis & BB 06.197 & Madagascar \\
\hline 5 & KF294603 & Cantharellus aff. decolorans & BB 06.146 & Madagascar \\
\hline 6 & KF294653 & Cantharellus aff. decolorans & BB 08.234 & Madagascar \\
\hline 7 & KF294654 & Cantharellus aff. decolorans & BB 08.278 & Madagascar \\
\hline 8 & KF294604 & Cantharellus aff. tanzanicus & BB 06.148 & Madagascar \\
\hline 9 & KF294605 & Cantharellus aff. tanzanicus & BB 06.149 & Madagascar \\
\hline 10 & KF294668 & Cantharellus afrocibarius & BB 96.235 & Zambia \\
\hline 11 & KF294669 & Cantharellus afrocibarius & BB 96.236 & Zambia \\
\hline 12 & KF294645 & Cantharellus albidolutescens & BB 08.057 & Madagascar \\
\hline 13 & KF294646 & Cantharellus albidolutescens & BB 08.070 & Madagascar \\
\hline 14 & KF294627 & Cantharellus altipes & BB 07.019 & USA \\
\hline 15 & KF294636 & Cantharellus altipes & BB 07.162 & USA \\
\hline 16 & KF294656 & Cantharellus ambohitantelyi & BB 08.336 & Madagascar \\
\hline 17 & KF294639 & Cantharellus amethysteus & BB 07.284 & Slovakia \\
\hline 18 & KF294642 & Cantharellus amethysteus & BB 07.309 & Slovakia \\
\hline 19 & KF294635 & Cantharellus appalachiensis & BB 07.123 & USA \\
\hline 20 & KF294663 & Cantharellus cerinoalbus & AV 06.501 & Malaysia \\
\hline 21 & KF294641 & Cantharellus cibarius & BB 07.300 & Slovakia \\
\hline 22 & KF294658 & Cantharellus cibarius & GE 07.025 & France \\
\hline 23 & JN940601 & Cantharellus cinnabarinus & BB 07.120 & USA \\
\hline 24 & KF294624 & Cantharellus cinnabarinus & BB 07.001 & USA \\
\hline 25 & KF294630 & Cantharellus cinnabarinus & BB 07.053 & USA \\
\hline 26 & KF294609 & Cantharellus congolensis & BB 98.039 & Tanzania \\
\hline 27 & KF294661 & Cantharellus diminutivus & DS 06.033 & Malaysia \\
\hline 28 & KF294638 & Cantharellus ferruginascens & BB 07.283 & Slovakia \\
\hline 29 & KF294674 & Cantharellus fistulosus & DT 43 & Tanzania \\
\hline 30 & KF294650 & Cantharellus ibityi & BB 08.196 & Madagascar \\
\hline
\end{tabular}




\begin{tabular}{|c|c|c|c|c|}
\hline No. & Accession & Taxon & Strain & Locality \\
\hline 31 & KF294651 & Cantharellus ibityi & BB 08.203 & Madagascar \\
\hline 32 & KF294628 & Cantharellus lateritius & BB 07.025 & USA \\
\hline 33 & KF294633 & Cantharellus lateritius & BB 07.058 & USA \\
\hline 34 & JN940597 & Cantharellus lewisii & BB 07.003 & USA \\
\hline 35 & KF294623 & Cantharellus lewisii & BB 02.197 & USA \\
\hline 36 & KF294637 & Cantharellus lilacinopruinatus & BB 07.221 & Slovakia \\
\hline 37 & KF294625 & Cantharellus minor Peck 1872 & BB 07.002 & USA \\
\hline 38 & KF294632 & Cantharellus minor & BB 07.057 & USA \\
\hline 39 & KF294655 & Cantharellus paucifurcatus & BB 08.320 & Madagascar \\
\hline 40 & KF294647 & Cantharellus platyphyllus subsp. Bojeriensis & BB 08.158 & Madagascar \\
\hline 41 & KF294648 & Cantharellus platyphyllus subsp. Bojeriensis & BB 08.160 & Madagascar \\
\hline 42 & KF294617 & Cantharellus platyphyllus & BB 98.012 & Tanzania \\
\hline 43 & KF294620 & Cantharellus platyphyllus & BB 98.126 & Tanzania \\
\hline 44 & KF294644 & Cantharellus quercophilus & BB 07.097 & USA \\
\hline 45 & KF294649 & Cantharellus sebosus & BB 08.162 & Madagascar \\
\hline 46 & KF294652 & Cantharellus sebosus & BB 08.234 & Madagascar \\
\hline 47 & JN940604 & Cantharellus tricolor & BB 06.180 & Madagascar \\
\hline 48 & KF294607 & Cantharellus sp & BB 06.179 & Madagascar \\
\hline 49 & KF294664 & Cantharellus subamethysteus & DS 06.218 & Malaysia \\
\hline 50 & KF294601 & Cantharellus subincarnatus subsp & BB 06.080 & Madagascar \\
\hline 51 & KF294602 & Cantharellus subincarnatus subsp & BB 06.096 & Madagascar \\
\hline 52 & KF294660 & Cantharellus subpruinosus & GE 07.080 & France \\
\hline 53 & KF294631 & Cantharellus tabernensis & BB 07.056 & USA \\
\hline 54 & KF294634 & Cantharellus tabernensis & BB 07.119 & USA \\
\hline 55 & KF294622 & Cantharellus tanzanicus & BB 98.040 & Tanzania \\
\hline 56 & KF294629 & Cantharellus tenuithrix & BB 07.035 & USA \\
\hline 57 & KF294626 & Cantharellus texensis & BB 07.018 & USA \\
\hline 58 & KF294659 & Cantharellus friesii & GE 07.077 & France \\
\hline 59 & KF294662 & Cantharellus cuticulatus & DS 06.283 & Malaysia \\
\hline 60 & KF294640 & Craterellus tubaeformis & BB 07.293 & Slovakia \\
\hline
\end{tabular}

Source: The researcher's data analysis 


\subsection{Phylogenetic analysis}

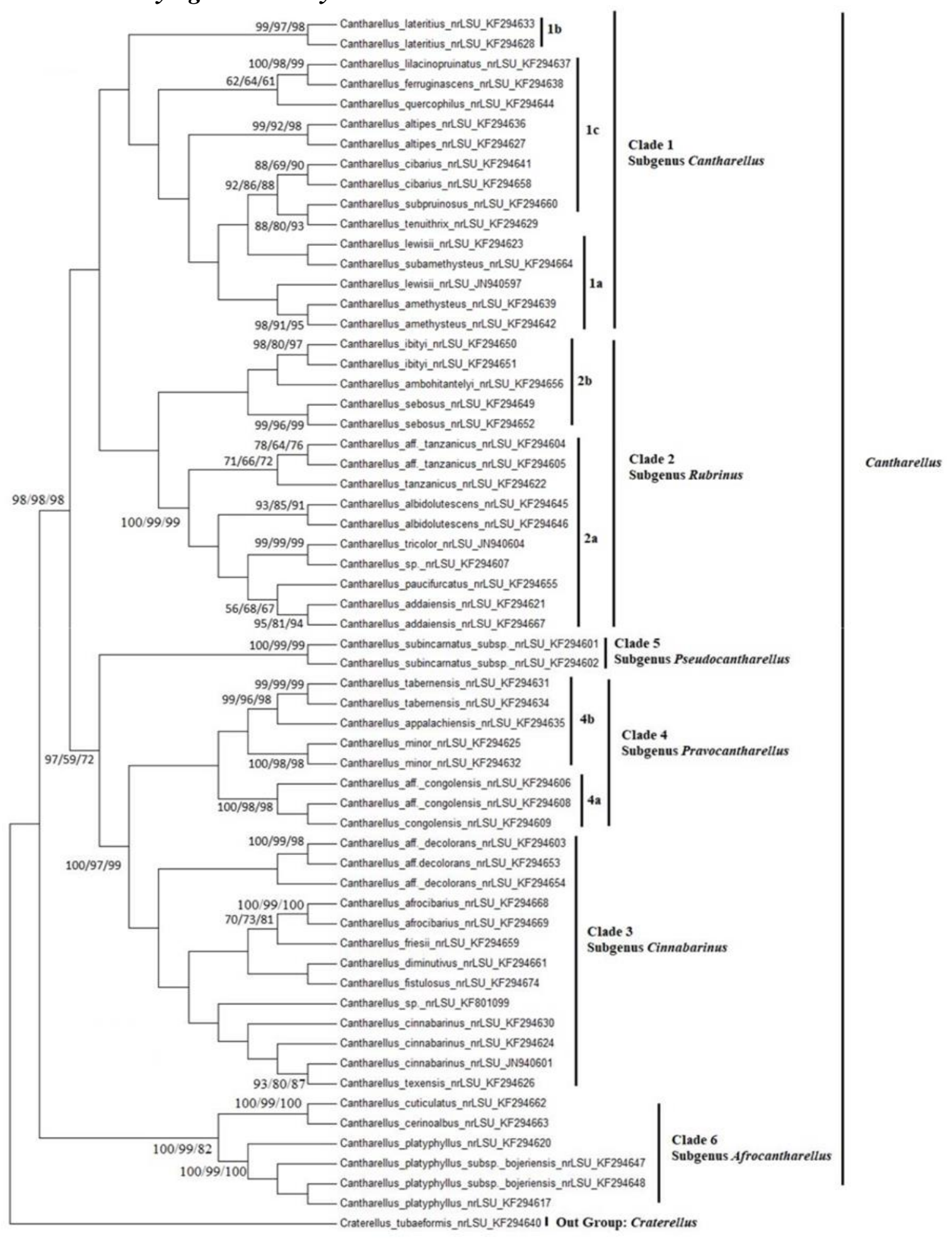

Figure 2. A phylogenetic tree was constructed via the maximum parsimony method. The Maximum Parsimony tree is shown with bootstrapping value of NJ/MP/ML 
The evolution model that was most fit with the observed data set was Kimura 2parameter, with following parameters: parameters $=121, \mathrm{BIC}=7891.413, \operatorname{lnL}=-3301.880$, $(+\mathrm{I})=\mathrm{n} / \mathrm{a},(+\mathrm{G})=0,24, \mathrm{R}=2.10, \mathrm{f}(\mathrm{A})=0,250, \mathrm{f}(\mathrm{T})=0,250, \mathrm{f}(\mathrm{G})=0,250, \mathrm{f}(\mathrm{C})=0,250, \mathrm{r}(\mathrm{AT})$ $=0,040, \mathrm{r}(\mathrm{AC})=0,040, \mathrm{r}(\mathrm{AG})=0,169, \mathrm{r}(\mathrm{TA})=0,040, \mathrm{r}(\mathrm{TC})=0,169, \mathrm{r}(\mathrm{TG})=0,040, \mathrm{r}(\mathrm{CA})=$ $0,040, \mathrm{r}(\mathrm{CT})=0,169, \mathrm{r}(\mathrm{CG})=0,040, \mathrm{r}(\mathrm{GA})=0,169, \mathrm{r}(\mathrm{GT})=0,040, \mathrm{r}(\mathrm{GC})=0,040$.

These parameters were applied to MEGA 6.0 to construct phylogenetic trees. As the results, the topology of neighbor-joining ( $\mathrm{NJ}$ ), maximum parsimony (MP), and maximum likelihood (ML) trees were similar to each other and to the trees from Buyck, Kauff, Eyssartier, Couloux, and Hofstetter (2014). 58 referent sequences from Cantharellus clade with 16 sequences for Subgenus Cantharellus (Clade 1), 15 for Subgenus Rubrinus (Clade 2), 12 for Subgenus Cinnabarinus (Clade 3), 8 for Subgenus Parvocantharellus (Clade 4), 2 for Subgenus Pseudocantharellus (Clade 5), 5 for Subgenus Afrocantharellus (Clade 6).

\section{Conclusion}

In general, we have successfully applied bioinformatics to construct a dataset basing on $n r L S U$ gene to support the identification of Cantharellus. This dataset is efficient to support the identification of the fungal samples, collected at the Langbian Mountain, Lam Dong in the future.

\section{ACKNOWLEDGMENTS}

We wish to express our thanks to the research project sponsored by Tay Nguyen Institute of Scientific Research.

\section{References}

Arora, D., \& Dunham, S. M. (2008). A new, commercially valuable chanterelle species, Cantharellus californicus sp. nov., associated with live Oak in California, USA. Economic Botany, 62, 376-391.

Buyck, B., \& Hofstetter, V. (2011). The contribution of tef-1 sequences to species delimitation in the Cantharellus cibarius complex in the southeastern USA. Fungal Divers, 49, 35-46.

Buyck, B., Kauff, F., Eyssartier, G., Couloux, A., \& Hofstetter, V. (2013). Molecular evidence for novel Cantharellus (Cantharellales, Basidiomycota) from tropical African miombo woodland and a key to all tropical African chanterelles. Fungal Diversity, 58, 281-298.

Buyck, B., Kauff, F., Eyssartier, G., Couloux, A., \& Hofstetter, V. (2014). A multilocus phylogeny for worldwide Cantharellus (Cantharellales, Agaricomycetidae). Fungal Diversity, 64, 101-121.

Dahlman, M., Danell, E., \& Spatafora, J. W. (2000). Molecular systematics of Craterellus: Cladistic analysis of nuclear LSU rDNA sequence data. Mycological Research, 104(4), 388-394.

Dunham, O. T. E., \& Molina, R. (2003). Analysis of nrDNA sequences and microsatellite allele frequencies reveals a cryptic chanterelle species Cantharellus cascadensis sp. nov. from the American Pacific Northwest. Mycological Research, 107(107), 1163-1177. 
Eyssartier, G., Stubbe, D., Walleyn, R., \& Verbeken, A. (2009). New records of Cantharellus speceis (Basidiomycota, Cantharellaceae) from Malaysian depterocarp rainforest. Fungal Divers, 36, 57-67.

Feibelman, T. P., Doudrick, R. L., Cibula, W. G., \& Bennett, J. W. (1997). Phylogenetic relationships within the Cantharellaceae inferred from sequence analysis of the nuclear large subunit rDNA. Mycological Research, 101(12), 1423-1430.

Fries, E. M. (1838). Epicrisis systematis mycologici, seu synopsis Hymenomycetum Elias Fries. Upsaliæ, 1836-1838. Vol. I. 8vo. Annals of Natural History, 4(21), 44-45.

Kumari, D. (2011). Studies on the diversity and nutritional value of Cantharellaceae of Western Himalayas, India. Retrieved January 10, 2018, from https://shodhganga.inflibnet.ac.in/handle/10603/223205

Kumari, D., Upadhyay, R. C., \& Reddy, M. S. (2011). Cantharellus pseudoformosus, a new species associated with Cedrus deodara from India. Mycoscience, 52, 147-151.

Persoon, C. H. (1797). Commentatio de fungis clavaeformibus sistens specierum hus usque notarum descriptiones cum differentiis specificis, nec non auctorum synonymis. Lipsiae, Germany: Apud Petrum Philippum Wolf.

Pilz, D., Norvell, L., Danell, E., \& Molina, R. (2003). Ecology and management of commercially harvested chanterelle mushrooms. General Technical Reports, 1-83.

Redhead, S. A., Norvell, L., \& Danell, E. (1997). Cantharellus formosus and the Pacific golden chanterelle harvest in Western North America, Mycotaxon, 65, 285-322.

Shao, C. S., Buyck, B., Hofstetter, V., Tian, X. F., Geng, Y. H., Yu, F. Q., \& Liu, G. P. (2014). Source Cantharellus hygrophorus, a new species in Subgenus Afrocantharellus from tropical Southwestern China. Cryptogamie, Mycologie, 35(3), 283-291.

Tibuhwa, D. D., Saviæ, S., Tibell, L., \& Kivaisi, A. K. (2012). Afrocantharellus gen. stat. nov. is part of a rich diversity of African Cantharellaceae. IMA Fungus, 3(1), 25-38. 